\title{
Influence of Emergency Medical Technician - Basic (EMT-B) course on Bachelor of Science Emergency Medical Services (BS EMS) (Paramedic) Program in Saudi Arabia
}

\author{
Natraj Y Rasa ${ }^{1} \quad$ Dr. Daifallah Alrazeeni ${ }^{2} \quad$ Dr. Ehtesham Ahmed Sharieff ${ }^{3}$ \\ 1.Faculty member, Prince Sultan College for emergency medical services (PSCEMS), king Saud University \\ (KSU), Saudi Arabia. \\ 2.Vice Dean for Academic Affair, PSCEMS, KSU and Formal Chair of Saudi Association for EMS (SAEMS), \\ SA \\ 3.EMS Program Director, PSCEMS, KSU, SA. \\ E-mail:*dalrazeeni@ksu.edu.sa, nrasa@ksu.edu.sa, esharieff@ksu.edu.sa.
}

\begin{abstract}
Students become extraordinary because of their strong foundations in the basic EMS skills and knowledge. In our BS EMS program, the main aim has always been to graduate extraordinary group of paramedic students. This is only possible by building strong foundations in communication, comprehension, knowledge and skills.

DOI: $10.7176 / \mathrm{JEP} / 11-33-06$

Publication date: November $30^{\text {th }} 2020$

\section{Introduction}

While assessing the extraordinary students of our college, many times, a question arose in mind that these students do not even need teaching. They are so good at what they are doing during in the later parts of the program. Students become extraordinary because of their strong foundations that they have laid for themselves with the help of academicians. Unfortunately extraordinary students are usually $<5 \%$. All students including the extraordinary 5 percentile require meticulous training. There are also students who are extremely challenged in their learning abilities, who may be $<5 \%$ like the extraordinary ones. Our program should suit both student types. As the first college outside the United States to be accredited from the Committee on Accreditation of Educational Programs for the Emergency Medical Services Professions (CoAEMSP), we have an aim for Excellency. Our aim has always been to graduate extraordinary group of students where every individual is as good as the group itself. This is only possible by building strong foundations in communication, comprehension, knowledge and skills.
\end{abstract}

\section{Familiarity}

Getting familiar to the content in an academic process helps develop knowledge, critical thinking, comprehension and mastery over skills. EMT-B course gives the familiarity to the students to expect what is in store in the subsequent semesters of the BS EMS program of PSCEMS, King Saud University. We can confidently say that the students will not be able to pull the strings together without having to know the complete academic package in the mind. This complete academic package though at a basic level is definitely required to process the information. EMT-B course in our program is the sub-consciousness of the paramedic. The paramedic's sub-consciousness will help process the higher intellectual challenges that will come later in their academic and clinical lives.

\section{Recollection}

Students once getting familiar with the content there will be a need to recollect the information. Ability to recollect the information is not the same amongst all humans. As academicians our goal is to safely graduate the students with abilities to perform at an acceptable level. Every paramedic should be able to perform the skills that are performed in a similar way by every other practicing paramedic. Ability to recollect information is as important as the knowledge, both recollection and knowledge builds comprehension. The brain starts working like the computer with a memory for that field of study. Our job as academicians should not end at executing our academic tasks, but our job ends only when the graduating students execute their expected tasks.

\section{Connecting the dots and Critical thinking}

Without the EMT-B course students will have increasing difficulty in comprehending to the higher cognition required courses such as cardiology, medical and trauma emergencies, pediatrics, geriatrics, gynecology and obstetrics. EMT-B helps students enter the class with a background information for the mind to process. The faculty of advanced courses of our program will find it very easy to sow the seeds of knowledge when the soil is already dug. Ability to connect the dots is what's making the students of our college different from others. 


\section{Mastery of Skills}

How can you master the skills? It's a time tested answer - Practice. Can we rely on the students' self-motivation to practice? The answer is No. Academicians should give opportunities to the students to practice so much so that the students master skills. How can we execute the plan? The answer would be - Repetitions. Can we blindly repeat the same skills. The answer is - No. So what should we do? We should do the testing. How can we test? Change the testing scenarios.

\section{Experience as a Teacher}

We break a course in to chapters to teach in our early teaching years. Since we ourselves as teachers haven't mastered the content yet. Once we master the content, the entire course becomes a single chapter for the teacher. We still deliver the course as chapters but then the difference this time is that every chapter is taught with connected dots.

\section{Experience as an Evaluator}

In 2014-15, during evaluation it was observed that many students were not able to measure Blood Pressure during their VII semester. On inquiring further it was found that vital signs as a skill was not done in any of the semesters. Each one of us assume that basic skill such as measuring blood pressure must have been covered by some or the other course. Since 2015-16 academic year we have officially included time and resources for measuring vital signs alone. In EMT-B course there were labs that used to be conducted but the students were not tested until the final exams. The following year mid-term practical exams were introduced and there were improved outcomes but that was not enough. Then testing in the form of quizzes in labs were introduced before the labs. Single-testing format to multiple-frequent-testing formats help students to recollect and retain the information. Students do not know to put effort to recollect until we compel them to recollect the information in the form of frequent-shortinterval testing. Currently the 2020 AHA guidelines is recommending the same which we have been successfully implementing since 2015.

\section{Performance enhancement}

What we need is to raise the bar of the advanced courses over EMT-B. For example: While we teach patient assessment in IV semester we need to make the students learn the assessment findings, differential diagnosis, provide treatment options. If we teach assessment part of patient assessment in IV semester there would not be any value additions to the students over what they learnt in the III semester. What to do with the assessment findings of patient assessment is what we need to focus in IV semester. Similarly, when it comes to the trauma course there should be some value addition over what the students have learnt in trauma module of their EMT-B course. Trauma instructor himself/ herself should raise the bar in his/ her own skills in delivering the trauma course. Since the difference between the basic trauma and advanced trauma is very minimal but the minimal difference should be efficiently executed and add value to the course. This hold true to all the other courses. Expecting efficiency from the students on the first attempt at learning the course would be our mistake as academicians. We should not struggle to explain alveolar respiration and cellular respiration to the students in IV semester's airway management. With respiration physiology already in mind we should be able to explain respiratory/ metabolic alkalosis/ acidosis to the students. What we lay foundation is exchange of gases, delivery of oxygen, what we should be able to do is raise the bar of the students in subsequent semesters.

\section{Possible Disadvantages of BS EMS Program without the EMT-B course}

a) Students' critical thinking and connecting the dots for all the courses will not be accomplished until the end of the program but for few extraordinary students. Their basic comprehension currently is starting at the end of semester III. It may not be at an advanced level at semester IV but the journey of critical thinking starts at the end of semester III which will eventually stabilize and strengthen by the end of VIII semester. Solidifies during the internship and clinical rotations. Otherwise students would have graduated and learn critical thinking only on real patients which may not be the ideal thing we want.

b) We have to consistently remind ourselves that it's not just about the program it's also about those students but are not as good as the top 20\%. So our program should suit and build the last-student-standing too. Our current design with EMT-B may not be the best in the world, although it has the potential to be one, but excluding EMT-B from BS EMS program definitely is going to cause trouble to the students.

c) Finally, everything is possible, we may directly start with advanced training to our students. The advanced training should anyway start at a basic level. EMT-B is the answer to the basic training for the Paramedic program. Only names are differing the philosophy of training will remind whether EMT-B as a course remains or not we still have to do the foundation. 
10. Summary

EMT-B is the best comprehensive value addition to BS EMS program without any second thoughts. There may be deficiencies in the process of delivery of both EMT-B and other courses. We need to work on those deficiencies in the bridge between EMT-B course and the rest of the courses of the Paramedic program. Absence of EMT-B course will leave the students confused over a period of 3 years. We are giving students the opportunity to space out their brains to think and comprehend about EMS as a profession by teaching basics and then upgrading them to advanced levels.

\section{Disclosure}

The authors confirm that they have no conflicts of interest.

\section{References}

1. VINCENT-LAMBERT, C.; BEZUIDENHOUT, J.; VAN VUUREN, M. J. (2014). Are further education opportunities for emergency care technicians needed and do they exist? African Journal of Health Professions Education, [s. 1.], v. 6, n. 1, p. 6-9. DOI 10.7196/AJHPE.285. Disponível em: http://search.ebscohost.com.sdl.idm.oclc.org/login.aspx?direct=true \&db=asn\&AN=96326500\&site=eds-live. Acesso em: 7 nov. 2020.

2. Mat-jizat JE. (2018). The Use of Spaced Learning as a Pedagogical Strategy in Enhancing Student Learning. International Association for Development of the Information Society. Accessed November 7, 2020. http://search.ebscohost.com.sdl.idm.oclc.org/login.aspx?direct=true \&db=eric\&AN=ED600766\&site=edslive 